\title{
DERECHO CON LITERATURA: UN ARQUETIPO LITERARIO EN TIEMPOS DE POSMO-PANDEMIA - UN NEOLOGISMO ACASO INESPERADO
}

\author{
LAW AND LITERATURE: A LITERARY ARCHETYPE IN POST-PANDEMIC TIMES \\ - AN UNEXPECTED CASE NEOLOGISM
}

\section{DIREITO E LITERATURA: UM ARQUÉTIPO LITERÁRIO EM TEMPOS PÓS- PANDÊMICOS - UM NEOLOGISMO DE ACASO INESPERADO}

\author{
LUIS MELIANTE GARCÉ \\ https://orcid.org/0000-0001-9636-2484 / https://www.linkedin.com/in/prof-dr-luis-meliante-3116ab22 / luimelgar@hotmail.com \\ Facultad de Derecho de la Universidad de la República - UDELAR \\ MONTEVIDEO - URUGUAY
}

\begin{abstract}
RESUMO
O direito como prática social discursiva multivocal, produtora de sentido e instituinte, desenvolve-se no quadro social interativo. Influenciado em sua discursividade, em seus aspectos teóricos, metodológicos e pragmáticos pela pósmodernidade que hoje parece estar em declínio, sofreu diversas alterações. Por sua vez, a atual ruptura da pandemia certamente o mobilizará ainda mais. A necessidade de uma ressemantização é vislumbrada ali, e a possível geração de um neologismo. Uma análise "crítico" em sentido estrito que opera num quadro interdisciplinar permite uma clara apreciação do vínculo Direito e Literatura, e da matriz narratológica do primeiro. Assim, ele abre caminho para ser considerado uma forma literária arquetípica que se desdobra em um parquete narrativo

Por outro lado, uma percepção hermenêutica como instrumento cognitivo, compreensivo-interpretativo e metodológico é reivindicada como valiosa e necessária para o Direito da época, pois também contribui para mitigar sua notória opacidade que certamente tende a aumentar em contextos disruptivos.
\end{abstract}

Palavras-chave: Direito com literatura, pós-modernidade, pósmo-pandemia, neologismo, arquetípico, narrativismo.

\begin{abstract}
Law as a multivocal discursive social practice, producing meaning and instituting, develops in the interactive social framework. Influenced in its discourse, in its theoretical, methodological and pragmatic aspects by post-modernity, which today seems to be in decline, it has undergone several changes. In turn, the current disruption of the pandemic will certainly mobilize you even more. The need for a resantization is seen there, and the possible generation of a neologism. A "critical" analysis in the strict sense that operates within an interdisciplinary framework allows a clear appreciation of the link between Law and Literature, and the narratological matrix of the former. Thus, it opens the way to be considered an archetypal literary form that unfolds in a narrative parquet On the other hand, a hermeneutic perception as a cognitive, comprehensive-interpretative and methodological instrument is claimed to be valuable and necessary for the Law of the time, as it also contributes to mitigate its notorious opacity, which certainly tends to increase in disruptive contexts.
\end{abstract}

Keywords: Law with literature, post-modernity, post-pandemic, neologism, archetypal, narrativism.

\section{RESUMEN}

El Derecho como práctica social discursiva multívoca, productora de sentido e instituyente, se desarrolla en el marco interactivo social. Inficionada en su discursividad, en sus aspectos teóricos metodológicos y pragmáticos por la posmodernidad que hoy parece declinar, fue objeto de diferentes alteraciones. Por su parte, la disrupción pandémica actual, es seguro que le movilizará aún más. Se vislumbra allí la necesidad de una re-semantización, y la posible generación de un neologismo. Un análisis “crítico" en sentido estricto que opere dentro de un marco interdisciplinario, permite apreciar diáfanamente el nexo Derecho con Literatura, y la matriz narratológica del primero. Se abre paso así para poder considerarlo una forma Literaria arquetípica que se despliega en un parquet narrativo. Por otro lado, una percepción hermenéutica como instrumento cognitivo, comprensivo-interpretativo y metodológico se reivindica como 
valiosa y necesaria para el Derecho de estos tiempos, pues contribuye a mitigar además, su consabida opacidad que de seguro tiende a aumentar en contextos disruptivos

Palabras clave: Derecho con Literatura, posmodernidad, posmo-pandémico, neologismo, arquetípico, narrativismo.

\section{SUMÁRIO}

INTRODUCCIÓN - 1 DERECHO CON LITERATURA EN TIEMPOS DE POSMO-LIQUIDEZ; 2 LA DISRUPCION PANDEMICA. NECESIDAD DE UNA RESEMANTATIZACION Y CREACION DE UN NEOLOGISMO: LA POSMOPANDEMIA; 3 DERECHO CON LITERATURA. EL DERECHO COMO FORMA ARQUETIPICA DE LITERATURA. NO OPACIDAD Y HERMENEUTICA; CONCLUSIÓN; REFERENCIAS.

\section{INTRODUCCIÓN}

\section{DERECHO CON LITERATURA EN TIEMPOS DE POSMO-LIQUIDEZ}

Umberto Eco, quien sin duda debe considerarse como uno de los pensadores más lúcidos de los últimos tiempos, en su vasta obra, nos legó un soberbio escenario intelectual que incursionó como es sabido, en libros y ensayos sobre semiología, estética, lingüística literatura y propiamente filosofía. Una obra singular, erudita y profundamente estimable.

En un texto editado poco antes de su muerte y que llama a su lectura permanente, expresó lo que sigue:

[...]La sociedad líquida empieza a perfilarse con la corriente llamada posmodernismo ( término comodín, que puede aplicarse a multitud de fenómenos distintos, desde la arquitectura a la filosofía y a la literatura, y no siempre con acierto).El posmodernismo marcó la crisis de las "grandes narraciones" que creían poder aplicar al mundo un modelo de orden; tenía como objetivo una reinterpretación lúdica e irónica del pasado, y en cierto modo se entrecruzó con las pulsiones nihilistas. No obstante, para Bordoni también está en fase decreciente. Tenía un carácter temporal, hemos pasado a través de él sin darnos cuenta siquiera y algún día será estudiado como el prerromanticismo. Se utilizaba para señalar un fenómeno en estado de desarrollo y ha representado una especie de trayecto de la modernidad a un presente todavía sin nombre[... $]^{1}$

Para Bauman, sigue diciendo Eco:

[...] ]entre las características de este presente en estado naciente, se puede incluir la crisis del Estado (¿qué libertad de decisión conservan lo Estados, frente al poder de las entidades supranacionales?). Desaparece una entidad que garantizaba a los individuos la posibilidad de resolver de una forma una homogénea los distintos problemas de nuestro tiempo, y con su crisis se ha perfilado la crisis de las ideologías, y por tanto de los partidos, y en general de toda apelación a una

\footnotetext{
1 Eco, U.: "De la estupidez a la locura. Crónicas para el futuro que nos espera”. Barcelona, Lumen, 2016,
} pp.9 y 10. 
comunidad de valores que permitía al individuo sentirse parte de algo que interpretaba sus necesidades[... $]^{2}$

La idea de "licuación" como metáfora sociológica, que bien supo explotar Eco, como es sabido y aclara el maestro italiano, pertenece a Zigmunt Bauman.

Para Bauman, la visión de la sociedad emergente de la idea de modernidad que se despliega con esa original idea funcional y traslativa del sentido de "liquidez", se opone a aquella propia de la modernidad "sólida", que era la modernidad del orden comunitario y estatal, preñado de capitalismo.

El sentido que Eco recoge a partir de la idea de "licuación" que propuso Bauman trasladado a lo social, resulta ser profundamente alarmante.

Perspectivas de fenómenos diferentes, tales como el de una crisis del concepto de comunidad, el aumento de un individualismo desenfrenado y de un marcado antagonismo así como de un subjetivismo exacerbado, la idea de una constante fragilidad y pérdida de los puntos de referencia; provocan necesariamente una visión cuasi apocalíptica que se resuelve en esa especie de "liquidez" baumaniana.

Pero lamentablemente, las cosas no terminan allí.

También se pierden, en opinión de Eco:

[...]la certeza del Derecho (la magistratura se percibe como enemiga), y las únicas soluciones para el individuo sin puntos de referencia, son aparecer como sea, aparecer como valor y el consumismo..."," el consumismo no tiende a la posesión de objetos de deseo con los que contentarse, sino que inmediatamente se los devuelve obsoletos, y el individuo pasa de un consumo a otro en una especie de bulimia sin objetivo...No solo los individuos sino la sociedad misma vive en un proceso de precarización[... $]^{3}$

De tal manera, como puede verse, Eco vaticinaba hace apenas cuatro años atrás, que este estado de "licuación" anunciado por Bauman, duraría bastante tiempo, y no se sabía hasta ahora, cómo salir del mismo. “[...]El problema - decía Eco - es que la política y en gran parte la intelligentsia todavía no han comprendido el alcance del fenómeno[...]” 4

Lo cierto que el vaticinio trajo consigo, a escala planetaria, algunas patologías muy perniciosas, tales como injusticia social, desigualdad material, problemas de tipo laboral, delincuencia más violenta y sofisticada, problemas medioambientales, déficits o deteriores en la legitimación y autocomposición democrática de los Estados Nacionales Todo ello, como es

\footnotetext{
${ }^{2}$ Eco, U.: ob. cit, nota 2. pp. 10.

${ }^{3}$ Eco, U.: ob. cit. nota 2, pp. 10 y 11

${ }^{4}$ Eco, U.: ob. cit. nota 2, pp. 11.
} 
notorio, repercute riesgosamente en el centro mismo del concepto de Derecho, así como asaz, en el propio concepto de Estado de Derecho no solamente en su sentido más tradicional, sino también en su forma nueva, - por lo menos para Latinoamérica, - aquella del llamado Estado Constitucional de Derecho.

Todo esto, claro está, sin contar otro tipo de problemas que afectan directa y particularmente a algunos países de Europa y claramente a Norteamérica y no a Latinoamérica,por lo menos directamente, - que de alguna manera se conectan con nuevas tipologías de fundamentalismos de sentidos inversos que se retroalimentan permanentemente. ${ }^{5}$

Pero, volviendo a Bauman, creador de la metáfora, al contrario de lo que pudiera pensarse y a diferencia de la mayoría de los casos de distopía social, esta situación de aquello que el autor entiende como una "nueva modernidad" y que deriva en una sociedad líquida, no es consecuencia de un gobierno dictatorial, ni de la subordinación, ni de la opresión o la esclavitud, ni tampoco, aludiendo con ello a Habermas, puede ser entendida como "un efecto de la “colonización de la vida privada" por parte del sistema, sino:

[...] Más bien todo lo contrario: la situación actual emergió de la disolución radical de aquellas amarras acusadas - justa o injustamente - de limitar la libertad individual de elegir o de actuar. La rigidez del orden es el artefacto y el sedimento de la libertad de los agentes humanos. Esa rigidez es el producto general de perder los frenos de la desregulación, la liberalización, la flexibilización, la creciente fluidez, la liberación de los mercados financieros, laboral e inmobiliario, de la disminución de las cargas impositivas,...de las técnicas de" velocidad, huida y pasividad"...en otras palabras técnicas que permiten que los agentes libres no se comprometan entre sí, que se eludan en vez de reunirse $[\ldots]^{6}$

Bauman entiende así que lo que se está produciendo, es un una suerte de " redistribución" y una "reasignación" de los poderes de la modernidad.

Por su parte, Javier Mateo Girón, sintetiza de una manera absolutamente compartible la especie que el propio Bauman nos proyecta, comparando - como una lógica oposición - dos fases evolutivas de la sociedad moderna, totalmente contrapuestas: “ la modernidad sólida”, como precedente a la actual, y que como hemos visto, en la tesis baumaniana se ha decididamente “licuado". Expresa el autor:

[...]la modernidad "sólida" era la modernidad preocupada por el orden y la modernidad del capitalismo pesado, duro, de producción, industrial y desarrollista (también esclavista vía contrato y ya no por las cadenas); la modernidad kantiana, racional, weberiana, del Estado-nación comunitarista o contractualista, de los derechos liberales y los avances sociales, los grandes e inamovibles valores, la

\footnotetext{
${ }^{5}$ Sobre este tema, puede consultarse: Meliante, L.: Latinoamérica en la región: "Sociedad líquida", decisión judicia y política. Un conflicto agudo apenas disimulado", en Revista Anales de la Facultad de Ciencias Jurídicas y Sociales. Universidad Nacional de La Plata. UNLP, No. 48- V 15, , pp. 1075-1105.

${ }^{6}$ Bauman, Z. : “Modernidad líquida”, FCE, Argentina, 2004, (3ª- Ed), pp. 11.
} 
ética del imperativo categórico, la fe en el progreso, el marxismo y la confianza en la emancipación; pero también de la fábrica fordista, la producción en masa, la división y la ética del trabajo, la cultura de masas, el darwinismo social, el genocidio racionalizado, el Gran Hermano, el Konzlager, la emergencia de las clases trabajadoras alienadas, de los ordenamientos jurídicos impermeables, de las fronteras infranqueables y del Estado totalitario y sus consecuencias y la invasión de la esfera de lo privado por lo público[... $]^{7}$

La era de la modernidad "sólida" entonces, de esta manera, ha llegado a su fin.

En la fase actual: modernidad liquida en el lenguaje de Bauman, o posmodernidad, o segunda revolución capitalista,- vocablos que pertenecen a otras semánticas ciertamente muy recurrentes pero compatibles con la idea baumaniana, "la solidez se ha licuado". Lo que sucede es que simplemente, como todo lo liquido, fluye.

Como puede apreciarse, hoy es el momento de lo efímero y cambiante.

Pero también sucede, que desde hace ya algún tiempo, también, en el marco del relacionamiento mundial, es el momento geo-político y económico de la "globalización", concepto muy viajero si los hay, y que no puede desligarse a su vez de aquel concepto de lo “posmoderno", cuyo declive anunciaba Eco como se viera líneas arriba.

Llegados a este punto, parece necesario efectuar algunas precisiones y ajustes, so riesgo de lo contrario, de perturbar al lector. Vamos entonces por tales ajustes.

Recuérdese por ejemplo, que Ulrich Beck distinguía tres aspectos claves en cuanto al aspecto globalizador ${ }^{8}$, a los que denominó : globalidad, globalización y globalismo.

Globalidad, según Beck, implica la cabal certeza del hombre contemporáneo y por ende de las distintas comunidades, de que hace tiempo que vivimos en una sociedad mundial y que la tesis de los espacios cerrados es ficticia. No hay entonces ningún país ni grupo que pueda vivir al margen de los demás. Queda claro pues, que las formas económicas, políticas y culturales - entre las que la Ciencia Jurídica obviamente se encuentra - , no dejan de entremezclarse y que las evidencias del modelo occidental deben justificarse de vuelta.

Globalización, según el mismo autor, es la forma de la globalidad de la segunda modernidad. En tal contexto los estados nacionales soberanos se entremezclan e imbrican mediante actores transnacionales, sus respectivas posibilidades de poder, sus orientaciones, sus identidades y entramados varios.

\footnotetext{
7 Mateo Girón, J. (2009): “. Zygmunt Bauman: una lectura líquida de la posmodernidad”. Relaciones internacionales (SI), No.9, nov.2009, ISSN16993950, disponible en : $\mathrm{http} / / \mathrm{www} / \mathrm{info} / \mathrm{ojs} /$.index.php?jorunal=Relaciones/nternacionales=page $=$ article $=o p=v i e w . p a t h \% 5 B \% 5 \mathrm{D}=12$ 8., pp. 3,4.

${ }^{8}$ Beck, U. cit. por Acosta, Y. en : Acosta: Y. "Sujeto y democratización en el contexto de la globalización. Perspectivas críticas desde América Latina. Editorial Nordan-Comunidad, Montevideo, 2005, pp. 28, y 127.
} 
Un diferenciador esencial entre la primera y segunda modernidad, en opinión de los autores que se vienen citando, es la irreversibilidad de la globalidad resultante, lo que de hecho significa que existe una afinidad entre las distintas lógicas de la globalización ecológica, cultural, económica, política y social que no son reducibles ni explicables las unas a las otras, sino que deben resolverse y entenderse en sí mismas y en mutua interdependencia.

Y por último una categoría ideológica clave: la ideología del globalismo, que es “[...]aquella concepción según la cual el mercado mundial desaloja o sustituye el quehacer político,[...]” es decir... (es) “[...]la ideología del dominio del mercado mundial o ideología del liberalismo... que ...procede de manera monocausal y economicista y reduce la pluridimensionalidad de la globalización a una sola dimensión, la económica[...]”9.

Se destaca así el presunto predominio del mercado mundial. Esta cuestión revela claramente el núcleo ideológico del globalismo, que se da de traste - dice Beck- con una distinción fundamental de la primera modernidad, a saber, la existente entre política y economía. Es decir, ... aquella tarea esencial de la política que era delimitar bien los marcos jurídicos, sociales y ecológicos dentro de los cuales el quehacer económico es posible y legítimo socialmente, se sustrae así a la vista o se enajena. ${ }^{10}$

El tríptico que se ha mencionado: globalidad, globalización y globalismo; y la generación de una filosofía subyacente tal como se consuma en términos generales en la sustentada por el movimiento posmoderno con todo su despliegue cultural, ya se encuentre en declive o no, conlleva tras su aparente racionalidad, una deshumanización creciente y con ella un elevado número de problemas pragmáticos en el ámbito del escenario social de los países latinoamericanos, claramente periféricos a los centros constitutivos del eje global hasta hoy dominante, euro-norte céntrico.

De tal manera, si bien podría llegar a entenderse como dice Eco, que el posmodernismo como estadio sociocultural y político está hoy en una fase decreciente, lo que es seguro que no estaría menguando, son algunas de sus características más destacables y perniciosas a las que se ha hecho referencia líneas arriba.

Tampoco puede dejar de decirse que tal momento histórico, con la condición altamente expansiva que se ha apuntado, es también - y a no olvidarlo - una fase de la última revolución capitalista, que con la algarabía globalizadora, ${ }^{11}$ usando sus profusos canales, trajo consigo,

\footnotetext{
${ }^{9}$ Beck, U., cit p. Acosta, Y. en ob. cit. nota 8, pp. 25.

${ }^{10}$ Acosta, Y.: ob cit. nota, 8, pp.29.

${ }^{11}$ Meliante Garcé, L..: “Contribución para una perspectiva filosóficamente crítica de la unidad básica del Derecho de Familia”, Anuario de Derecho de familia y Sucesiones”, No. 3. FCU, Montevideo, 2015,pp. 149-
} 
además de fuertes criterios de incidencia transnacional en la distribución económica, un relegamiento expreso de la subjetividad en todos los aspectos posibles.

Entonces, para que quede claro, globalidad, globalización, globalismo, licuación y además la disputa entre la díada opositiva modernidad-posmodernidad, constituyen términos de un contexto social, cultural y político sumamente imbricado que, si acaso no se manejaran con cierta claridad sus puntos de referencia pragmática y sus interconexiones recíprocas, provocarían una suerte de disociación de sus contenidos, que, metafóricamente expresado, resultaría una muestra de clara esquizofrenia lingüística y cultural.

En este contexto tan peculiar, sería absolutamente ilusorio pensar que el hábitat cultural contemporáneo, en su más amplia dimensión, no haya sido impactado.

En varias oportunidades por ejemplo, siguiendo a Doederlein Schwartz me he preocupado en señalar, que la literatura contemporánea está caracterizada por su fragmentariedad, y por tanto resulta pasible de su complementariedad en cualquier momento.

Estos aspectos - fragmentariedad y complementariedad - serían el resultado de la evolución de algunos movimientos literarios actuales tales como el esteticismo, naturalismo, realismo, posmodernismo, etc., entre los cuales precisamente el "posmodernismo literario", es el marco de expresión en donde se presentan con mayor nitidez tales características. ${ }^{12}$

Dentro de estos dos aspectos inherentes al "posmodernismo literario" señalados por el autor brasileño, surgen a su vez derivaciones consecuenciales que se concretan en dos variables específicas: falta de certeza y policontextualidad, lo que podría llevar también a que la denominada posmodernidad histórico - cultural, pudiera ser concebida ya no solamente como un nuevo período histórico, sino más como una negación de la modernidad, ${ }^{13}$ aserto que parece guardar mucha conexión con la lúcida idea planteada por $\mathrm{Eco}^{14}$, referida al carácter temporal, episódico y nihilista de esa época.

En lo que dice relación con el Derecho, al asumirse éste como una práctica socio-culturaldiscursiva productora de sentido, constitutiva e instituyente, que se desarrolla en el marco interactivo social y en donde su matriz generativa puede decirse que es multívoca, debe

161; Meliante Garcé, L.: “La sociedad líquida y el derecho al Derecho", en Revista Crítica de Derecho Privado, La Ley-Uruguay, 2017, pp. 3,4.

12 Doerdelein Schwartz, G.: "Um admirável novo direito: autopiese, risco e altas tecnologías sanitarias. En Direito \& literatura. Reflexôes teóricas, Porto Alegre: Livraria do Advogado, 2008, pp. 192-.208.

${ }^{13}$ Doerdelein Schwartz, G.: ibídem, y Meliante, L. y Sosa, M.J.: "Derecho y literatura: Interdisciplinariedad, cruces inevitables y réditos posibles", en Cuadernos del Claeh, Vol. 37, No. 108, 2018, $h$ ttps://doi.org/10.29192/CLAEH.37.2.3.

${ }^{14}$ Eco, U.: "De la Estupidez a la locura. Crónicas para el futuro que nos espera. Lumen, Barcelona, 2016,pp. 9-10. 
entenderse que su funcionalidad se despliega siguiendo la evolución política y social en el más amplio sentido. ${ }^{15}$

Por todo ello, resulta obvio que tampoco ha salido indemne de la sacudida posmo-líquida.

No solamente el discurso, sino todo lo concerniente a "lo jurídico", categoría a la que se apela en este acotado texto y que debe ser entendida en el marco del mismo como una contextualidad semántica en su origen, pero predominantemente orientada a lo pragmático, que es parte primordial de aquella praxis multívoca y constitutiva tal como se ha caracterizado al Derecho; resultaron también afectados por la falta de certeza y la policontextualidad, de forma paralela a como lo fueron la literatura y otros constructos culturales, puesto que además y especialmente, el Derecho constituye, según entiendo, una forma de Literatura arquetípica. Esos dos aspectos que afectaron a "lo jurídico", se encuentran además claramente entrelazados

Por ejemplo en el contexto de la complementariedad, resultó claramente afectado el marco discursivo del Derecho pues se hipotecó la rigurosidad de la textualidad jurídica en función de su comunicabilidad. (Teubner).

Y en cuanto a la otra variable a que se aludiera - la policontextualidad - engarzada con la primera, se tradujo en una ausencia de centralidad productiva jurídica, en sentido amplio. Esto es, la policontextualidad debe ser comprendida en forma polivalente, y repercute como puede inferirse, en el sistema de fuentes del Derecho, con la promoción de instalación de fuentes creadoras de derecho alternativas, que naturalmente erosionan la centralidad del lugar que ocupaba la legislación en tal contexto, por lo menos en la modernidad sólida. ${ }^{16}$

De tal manera, si se sigue dentro del marco de ese contexto sociológico metafórico propuesto por Bauman, el Derecho parece ser en la época presente, menos técnico, menos autónomo, menos garantista, menos seguro y vehículo de intereses contingentes que fluyen en forma permanente.

Economía, Política y todo el aparato del contexto comunicacional, incidíeron siempre, pero inciden ahora mucho más, de manera constante, muy severamente y casi con un sentido de arritmia, en el derrotero de esa evolución.

\footnotetext{
${ }^{15}$ Cárcova, C. Ma..: "Las Teorías Pos positivistas", Lexis Nexis, Buenos Aires, 2007, pp. 162. Meliante Garcé, L.: "La Crítica jurídica Latinoamericana. De la invisibilidad a su consideración en la Doctrina Nacional, en Revista de la Facultad de Derecho No. 36. FCU, Montevideo, 2014, pp.272.

${ }^{16}$ García Rubio, M.P.: "Sociedad liquida y codificación", en Anuario de Derecho Civil,V.69, No.3, Ministerio de Justicia, Boletín Oficial del Estado,2016, España,pp.746,Meliante Garcé, L." Latinoamérica en la región: Sociedad liquida, decisión judicial y política. Un conflicto agudo apenas disimulado.", en Revista Anales Revista Anales de la Facultad de Ciencias Jurídicas y Sociales. Universidad Nacional de La Plata. UNLP, No. 48/2018, 2015, pp.1078 y ss.
} 
Pero, como veremos en el apartado que sigue, el presente año 2020, trajo para el mundo una situación inesperada, por lo menos para gran parte de él.

\section{LA DISRUPCION PANDEMICA. NECESIDAD DE UNA RESEMANTATIZACION Y CREACION DE UN NEOLOGISMO: LA POSMO-PANDEMIA.}

Desde principios de este año que ya finaliza, el mundo - nuestro mundo - a escala planetaria se ha visto impactado por la incertidumbre y el miedo, como consecuencia de la irrupción de un fenómeno pandémico producto del denominado "Covid-19", una mutación viral cuyo origen real - dejando de lado cualquier hipótesis de tipo conspirativo - se sabrá seguramente de aquí a un largo tiempo.

Es decir, dentro de algunos lustros, seguramente agencias gubernamentales de países dominantes, aunque el eje de dominio pueda haber ya variado de polo, - cosa harto probable permitirán que se filtren siempre de a poco, informaciones parciales desclasificadas de lo que realmente ha sucedido tras la enfermedad y mortalidad globalizadas.

Lo cierto es, que en nuestro presente, casi de un día para otro, proliferaron enfermedad, muerte, inseguridad, distanciamiento social, cambio radical en los hábitos de higiene, afectación de la movilidad ciudadana, interrupción en el sistema educativo, modificaciones sustanciales en las condiciones de trabajo dependiente y en la actividad empresarial.

Hubo una sacudida frontal en la linealidad del modo productivo y en la circulación jurídico negocial, y también como resultado de la endemia encasillada en cada país, una cruda visibilización de la vulnerabilidad social, sanitaria y económica de muchas personas, así como en ocasiones, algunos aspectos no exentos de laxitud moral y violencia de diversa naturaleza.

De ello no ha salido indemne ningún país de la aldea global.

La incidencia de todo ello varió, claro está, según las distintas perspectivas que del infausto tuvieron las diferentes formaciones sociales, así como también en el mismo sentido, su eficacia estuvo en directa relación con el modelo y la rapidez del tipo de respuesta ${ }^{17}$ que frente

\footnotetext{
17 En su momento el gobierno uruguayo, advertida la crisis pandémica, tomó rápidas medidas. Algunas determinaron la suspensión y clausura de determinadas actividades en diversas áreas, (laborales, educativas, culturales, entretenimientos en sentido amplio, reducción del transporte y la circulación en general, etc.), se creó el denominado GACH (Grupo Asesor Científico Honorario) conformado por destacados científicos uruguayos), con el fin de efectuar un seguimiento y asesoramiento al Gobierno respecto del infausto pandémico, y en forma concomitante se apeló y exhortó a la ciudadanía a que acompañara todas las medidas de prevención que implementaron las autoridades de la salud, lo que encontró en general salvo excepciones, una respuesta de acatamiento y elogiable correspondencia con lo solicitado, que se nutrió también con la dedicada y responsable actitud que asumió el personal de la salud
} 
DERECHO CON LITERATURA: UN AROUETIPO LITERARIO EN TIEMPOS DE POSMO-PANDEMIA UN NEOLOGISMO ACASO INESPERADO

al impacto pandémico se adoptaran por los distintos Estados. Por supuesto que todo esto ocurrió al margen de los protagonismos, muchas veces sorprendentes, asumidos por algunos líderes políticos de países hegemónicos ${ }^{18}$.

Por otro lado, en búsqueda de un nuevo lenguaje que acompañara la conmoción, se adoptó rápidamente a nivel general, el concepto absolutamente contradictorio, versátil y acomodado de "nueva normalidad", destinado a instalar una semántica que insistentemente machacada, fue dirigida al imaginario social para dar cuenta de algo supuestamente "nuevo" y "normal", cuando en realidad de lo que se trata, es que el acontecimiento es el consecuente de los cruentos y dañosos cambios que provocó y seguirá provocando una clara disrupción de características épicas, naturalmente anormal, para la que el mundo en pleno, evidenció no estar preparado.

También, con el mismo destino de dirección hacia el imaginario social, aventurando un eventual mundo posible, como resultante pos pandémico, se comenzó a hablar casi enseguida de

en todos sus niveles. Se instaló un sistema de seguimiento de la evolución viral y un sistema de comunicación de los resultados dirigido a la población. El Sistema Nacional Integrado de Salud (SNIS), regulado por Ley 18.211 de 5/12/2007 con las modificaciones y agregados efectuados por las leyes 18.731 y 18.732 de $7 / 1 / 2011$, normas que reglamentan el derecho a la protección de la salud que tienen todos los habitantes del República, fue recibido por las nuevas autoridades, como herencia de la administración anterior, funcionando en forma por demás correcta, eficiente y organizada, lo que facilitó el seguimiento y el adecuado tratamiento según la gravedad de los casos. Hoy, a nueve meses que se detectara el primer caso viral, la situación, lamentablemente ha variado sustancialmente. El salto cuantitativo de casos, no es precisamente casual, sino causal, y lo que en principio fueron brotes, hoy es una ola gigantesca. La endemia tiene circulación social, y su transmisión proviene de diversas variables que exceden la mera arremetida de la circulación más acelerada de las mutaciones virales. En parte el aflojamiento de las restricciones que en muchos casos debieron ser necesariamente más severas, así como la apertura de la actividad económica sin ejercer durante un extenso lapso estrictos controles de seguridad más que exhortaciones, como también a nivel de la ciudadanía, el natural desgaste y agobio físico y sicológico padecido, se tradujeron finalmente en un no acatamiento bastante generalizado a las protecciones de autocuidado y cuidado social individual y colectivo necesarias, lo que contribuyó también, junto con todo lo expresado, a que en grado acelerado se derivara en lo que hoy es una situación alarmante para todo el país. Sin contar que la mayoría de los casos se centran en la capital del país, - Montevideo,- en Departamentos aledaños, y en aquellos que tienen frontera seca con la República Federativa del Brasil, lo cierto es que el avance viral se ha desplegado por todo el territorio de la República de manera exponencial. Ello ha descolocado a las autoridades nacionales y sometido a la población, e incluso al propio sistema de salud, a una gran incertidumbre y a un estado de alerta grave, que al comienzo de la disrupción pandémica, era absolutamente impensado. Es posible por ende que Uruguay se encuentre ahora, en un momento realmente crítico.

${ }^{18}$ No pueden dejar de mencionarse por ejemplo, muchas de las sorprendentes reacciones y comentarios públicos de algunos líderes mundiales, cuyas naciones están entre los países de nuestro planeta que encabezan el mayor número de casos de infectados por el Covid-19, así como los mayores números de víctimas mortales. En general hubo actitudes de cuestionamiento a las formas de adopción de precauciones y de contralor público para evitar la circulación del virus, así como respecto del tratamiento científico de la pandemia, junto con una visión descalificadora del centro de gravedad mayor de la misma, esto es la salud pública, para priorizar la economía. Estos comentarios han dado vuelta y sorprendido al mundo. La inclusión de elementos cuasi mágicos en las narrativas empleadas por los protagonistas, las hicieron aparecer, de alguna forma. cercanas al realismo mágico literario. 
los primeros momentos de la pandemia, en términos de epifanía, de una suerte de vaticinio de un esperado "día después", que a ciencia cierta, resulta impredecible saber cuándo comenzará. Finalmente, el giro que prometía un pronto final feliz, dejó de circular, seguramente como producto de evidencias fácticas y trágicas.

Estos aspectos, sin duda por todos conocidos, no resultan ser inocuos tampoco para la cultura, referida en sus términos más amplios, tal como ha venido siendo considerada en este trabajo.

Sin ser reiterativos, vale decir que si el impacto recae también sobre la cultura en tales términos de amplitud, todas las prácticas sociales y todos los saberes que le conciernen, no resultarán para nada indemnes frente al fenómeno pandémico, como no lo resultaron antes en otros contextos de cambios socio-culturales. $Y$ ahora, frente a lo disruptivo, mucho más entonces.

En lo que a este trabajo concierne e interesa decir, Literatura y Derecho resultarán conmovidos, y sin lugar a dudas, sus narrativas recogerán el derrotero y los rastros pandémicos.

Ambos saberes ya habían resultado afectados por la algarabía globalizadora, con la ideología del globalismo que le es inherente, aceptada y promovida desde el movimiento “posmoderno ", que además, como se ha hecho referencia, no puede desligarse del estado de licuación social respecto del cual nos advertió Bauman.

Podría entonces formularse la siguiente pregunta: ¿si Derecho y Literatura, como prácticas culturales socio-discursivas, venían siendo ya objeto de cambios sustanciales al margen de lo pandémico, cuánto lo serán ahora, en este escenario crítico y de total desacomodamiento social?

La respuesta a la misma parece reclamar inmediatamente, un sentido afirmativo, pero con prevenciones. En efecto, si se arriesgara un enunciado con ese contenido afirmativo a secas, y sin que ello signifique asumir una postura elusiva, debe decirse que tal respuesta, además de contingente, sería prematura.

Profundicemos aún un poco más.

Puede interpretarse que el acontecimiento pandémico, de alguna manera, pareció acomodarse inicialmente al casi infranqueable individualismo deshumanizante, a la justificación nihilista, a la desesperanza, o alguna que otra de las cuasi trágicas categorías fuertes promovidas desde aquella supuesta racionalidad que instaló la visión posmoderna y licuada de una realidad ya de por sí desacomodada. Es decir, de otra manera, lo pandémico parece no desentonar mucho con lo posmoderno. 
Si bien puede aventurarse pragmáticamente una correspondencia categorial posmopandémica, aquello que en principio aparece como un sorpresivo infausto que asaltó la salud y como consecuencia la estabilidad socio-económica a escala planetaria, constituye como se viera, una clara cuestión claramente disruptiva.

No obstante, pese a ello, generó también, paradójicamente en la mayoría de los casos, reacciones muy humanas, actitudes de lograda e inusitada solidaridad colectiva, ${ }^{19}$ que fueron claramente a contrapelo de muchos de los posibles malhadados vaticinios posmodernos y líquidos.

Existe entonces una situación socio-cultural, que merece su re-semantización mediante la creación de un neologismo que se considera apropiado. Puede decirse entonces, que estamos en realidad, en un contexto social y cultural posmo-pandémico.

Instalados así en este contradictorio marco posmo pandémico vigente, lo que resulta evidente y surge bajo una mirada inmediata, es la inicial estupefacción del sistema social tanto en sus aspectos subjetivos, materiales, comunicacionales e instrumentales, en donde "lo jurídico" con "lo literario", constituyen solo un enclave sub-sistémico parcial diferenciado, del sistema social general, y que además se encuentra en un permanente flujo de relacionamiento con el mismo, con su ambiente, y naturalmente con el resto de los subsistemas parciales.

Es claro que un sistema estupefacto, tiende en lo inmediato en forma espontánea, a reaccionar con los restos salvados de lo que quedó de la emergencia catastrófica de la crisis, en procura de reamoldar o reacondicionar sus contenidos.

En ese trance de reacción sistémica, pueden buscarse posibles comprensiones en base a la apuesta a una respuesta autopoiética. Esto, si bien adecuado, solo resulta ser una forma de actitud prudente respecto de lo que aún se encuentra en curso e implicado en cambios vertiginosos y constantes, en acomodamientos sociales de inusitada rapidez, y sobre todo dentro el marco persistente de una clara incertidumbre instalada como signo prevalente.

Como se expresara líneas antes, en lo atinente al Derecho desde la irrupción de la supuesta racionalidad posmoderna, se produjeron movilizaciones profundas en variados aspectos, y muchas de ellas en el acontecimiento pragmático del artefacto jurídico, que también,

\footnotetext{
${ }^{19}$ La solidaridad social, funcionó también al margen del apoyo estatal, que corrió por otros carriles formales: creación del fondo Covid 19, readaptaciones del sistema de seguro por desempleo, algunos incentivos dirigidos a determinados grupos de actividad afectados, etc. En el marco venido desde el escenario estrictamente comunitario no estatal, se apreció una enorme proliferación de ollas populares que funcionaban y funcionan aún en zonas carenciadas, exclusivamente mediante donaciones de alimentos y enseres aportados por los ciudadanos, creación de grupos de asistencia social, recolección de donaciones de ropa y alimentos no perecederos organizados por instituciones y movimientos sociales, para ser distribuidos entre los más necesitados, etc.
} 
obviamente es literario. De ello se ha dado cuenta en otra publicación, en donde incluso se sugirió adoptar el concepto de "posmo liquidez" para insinuar una adaptación de un posible entrelazamiento entre los resultados de los expulsos posmodernos y la licuación societaria sugerida por Zygmunt Bauman ${ }^{20}$, cuestiones ambas ya abordadas en este trabajo.

Entonces, vistas así las cosas, podemos ahora enfrentarnos a una pregunta más concreta, tal como la siguiente: ¿entre influjos posmodernos, autopoiesis, invasiones líquidas y emergencias pandémicas, es decir, en base a la re- categorización funcional al neologismo que se propone esto es lo posmo-pandémico - cuál sería la mirada posible para un abordaje del Derecho con Literatura, que pueda garantizar, aunque sea en parte, que no se transforme en algo dramáticamente opaco?

Se verá esto en el apartado que sigue.

\section{DERECHO CON LITERATURA. EL DERECHO COMO FORMA ARQUETIPICA DE LITERATURA. NO OPACIDAD Y HERMENEUTICA}

En un escenario de riesgosa sinuosidad que se pretende ahormar bajo aquella categoría no exenta de cierta soberbia, a la que se denominó “nueva normalidad” para denominar a la posmo-pandemia, que en realidad resulta ser una compleja disrupción, nada más alejada de lo normal: ¿cuál podría ser una respuesta acerca de cómo acompañar las particularidades de aquel Derecho con Literatura que puede asomar?

De acuerdo al todo lo que se ha venido exponiendo en este trabajo, vale reconocer que en el marco cultural, entre otras cosas, las consecuencias propias de los expulsos del discurso posmoderno literario (falta de certeza, policontextualidad) afectaron como se vio, al Derecho, puesto que éste no es otra cosa en su conformación discusiva, que una forma de arquetipo literario.

No debe olvidarse tampoco que, desde otras perspectivas, fue también afectado por aquellas incidencias que provienen de una licuación inespecífica en términos baumanianos, y en lo más inmediato hoy, por las emergencias pandémicas y pos pandémicas, éstas últimas tan solo meramente especulativas y escasamente visibles, en ese pos e ilusorio "día después", que como se viera, está lejos de llegar.

\footnotetext{
${ }^{20}$ Bauman, Z. : Ob. cit. nota 17, ibídem,.
} 
En tal contexto, constituye una de las tesis de este trabajo, postular dentro de un marco autopoiético, la utilización revalorizada y constante del recurso hermenéutico como un instrumento válido y solvente, para realizar abordajes hacia "lo jurídico" como arquetipo literario, en un tiempo de creciente inestabilidad sistémica.

Si se hilvanan todos estos conceptos que marcan la inserción de "lo jurídico-literario" en la realidad socio cultural actual, podemos concluir que el Derecho como arquetipo literario, o si se quiere Literatura arquetípica, requiere hoy como nunca, en forma necesaria, un abordaje hermenéutico. ${ }^{21}$

Resulta correcto decir que el tema del abordaje "hermenéutico" al que se alude, no es exclusivo de una perspectiva "crítica" sobre el Derecho, ni tampoco excluyente de la aplicación de otros modelos posibles, pero sí es uno de ellos, que se entiende altamente provechoso, y por ende se encuentra en gran parte capitalizado por este modo "crítico" de comprender "lo jurídico".

Por ejemplo, en términos de Honneth, por citar solo a alguno de los últimos herederos del pensamiento crítico de la Escuela de Frankfurt, se postula un carácter abierto, hermenéutico, procedimental para el Derecho, ${ }^{22}$ para lo que debe requerirse además, como se sostiene en este texto, un intenso estudio de los niveles de comunicación, una profundización de una perspectiva semiológica y lingüística que involucre al artefacto jurídico para su mejor comprensión, así como un análisis dedicado y específico de los sectores de la realidad socio-política que se relacionan con el mismo, todo amparado en la búsqueda permanente de la confluencia interdisciplinaria, en donde lo literario se transforma en pura inherencia.

Por otro lado, la aceptación o por lo menos la discusión de la complejidad social en de la manera que Luhmann propone, esto es en una perspectiva sistémica a la que parcialmente se aludiera líneas antes, completarían un set de herramientas sin duda proficuas para aplicar a la situación planteada.

Estos aspectos, constituyen un marco propicio para seguir dando cuenta de lo que no se ha relevado aún del fenómeno jurídico contemporáneo, y se estima que desalojarlo de ese entorno, contribuye a incrementar su opacidad, como expresó hace ya tiempo Carlos María Cárcova, concepto que necesariamente debe diferenciarse de la ignorantia iuris. ${ }^{23}$

\footnotetext{
${ }^{21}$ Streck, L.: “Crítica Hermenêutica do Direito”, Porto Alegre, Livraria do Advogado, Editora, 2016,pp.11.

22 Honneth, A. (2009): «Lo otro de la justicia. Habermas y el desafío ético del posmodernismo». En Honneth, A. Crítica del agravio moral. Patologías de la sociedad contemporánea, Buenos Aires: Fondo de Cultura Económica, 2009, p. 179.

${ }^{23}$ Cárcova, C. Ma..: “ La opacidad del Derecho”, Madrid, Trotta, 2006.
} 
En las sociedades democráticas actuales, el desconocimiento del Derecho afecta a la sociedad en su conjunto, y muy poco se ha hecho, dice el autor, “[...]para socializar a los súbditos en el conocimiento del Derecho[...]"24

El reclamo hermenéutico no es entonces meramente antojadizo. Su despliegue remite por inherencia al acercamiento cognitivo, al contexto de interpretación en la praxis de "lo jurídico" como forma arquetípica literaria; y de suyo ésta, la interpretación lograda, se expande hacia la búsqueda de significaciones, esto es, hacia la búsqueda de sentidos, que luego en su proyección pragmática van al encuentro de instancias performativas en el campo que se analiza.

En este contexto, Enrique Marí entendía con Gadamer, que la interpretación no es un acto complementario y posterior a la comprensión, pues comprender es interpretar, y la interpretación es la forma explícita de la comprensión.

Por su parte la comprensión, en un contexto hermenéutico, tal como se postula en el presente texto, está plagada de pre-comprensiones, de desigualdades, de asimetrías, de contingencias, que de alguna manera deben ser tamizadas por el propio acto unívoco de comprensión-interpretación, que en rigor está en manos del sujeto que comprende.

Posteriormente la aplicación, será así también un momento particular del proceso hermenéutico, tan importante como lo son la comprensión y la interpretación.

Desde esta perspectiva, comprender es también aplicar, ${ }^{25}$ y aplicar, tal como también se sostiene en este trabajo, es necesariamente comunicar.

Volviendo a los amplios ejes conectivos de una necesaria interdisciplinariedad, expresaba Mari, por ejemplo, que ni el Derecho ni la Literatura, aceptado su nexo intemporal, así como tampoco ninguna otra expresión de la estética, tienen la más mínima posibilidad de convertirse en campos sobre los que se pueda construir algo puramente racional, asociado racional con empírico y lógico metodológico. ${ }^{26}$

De tal manera, como refiere también Carlos María Cárcova, ${ }^{27}$ analizando el tema de la “verdad", el conocimiento actual, restituye la relación entre el conocimiento filosófico y el científico y supera así las otrora infranqueables fronteras entre esas dos culturas. Es así, expresa, que los desarrollos de la teoría lingüística en relación con las prácticas de producción de sentido, por una parte, y por la otra, los que aportan las teorías sistémicas con su conjunto de insumos

\footnotetext{
${ }^{24}$ Carcova, C. Ma. : Ob. cit. nota 24, , pp.38,39.

${ }^{25}$ Marí, E.: «Derecho y literatura. Algo de lo que sí se puede hablar pero en voz baja», DOXA, 21, II, 253287, 2008, pp. 261.

${ }^{26}$ Marí, E. : Ob. cit. nota, 16, pp. .282.

27 Cárcova, C.Ma.: "Verdad o verosimilitud", Conferencia Plenaria, del XXIX Congreso de la Asociación Argentina de Filosofía del Derecho, 1,2 y 3 de Octubre de 2015, Ushuaia, Argentina. 2015.
} 
provenientes de la neurociencia, la biología, la cibernética de segundo orden, la autopoiesis, se convierten en un arsenal que el Derecho actual no debe despreciar.

Y como consecuencia, el resultado es que la epistemología actual se ha complejizado y al mismo tiempo enriquecido de manera proficua. Por tanto, concluye, la cuestión de la "verdad" parece haber perdido la centralidad de antaño y hallarse sometida a una deriva a la vez incierta y apasionante.

Por ende la perspectiva hermenéutica, de cuyo centro emerge la verdad pero ya no en sentido ontológico, sino tan solo como "verosimilitud", esto es como algo probablemente verdadero, resulta así un concepto clave en este contexto de "lo jurídico" como forma literaria arquetípica.

Tanto en el Derecho como en la Literatura y en clara obviedad con el Derecho en tanto se acepte apreciarlo una como forma literaria arquetípica, la imaginación abre nuevas puertas a la comprensión de la realidad, "presiente" su transformación, ${ }^{28}$ lo que va en sintonía con el notable proceso hermenéutico, puesto que ese presentimiento, opera claramente como una precomprensión que, como se sabe, configura una clave de inicio privilegiada de toda situación hermenéutica, al decir de Gadamer.

Pero el tema no concluye allí.

Puede entenderse válidamente, que si se acepta la indiscutible dinámica interdisciplinaria entre Derecho y Literatura, así como el aprovechamiento pleno del recurso hermenéutico, queda al desnudo un sustrato de singular valor estructural.

En efecto, el cruce disciplinar Literatura con Derecho o su transposición lingüística Derecho con Literatura, refieren a una contextualidad propia de ambos saberes, que desde el punto de vista de la estilística discurso-expresiva, se consolida en el marco narratológico que puede adjudicarse tanto al Derecho como a la Literatura, o si se quiere asumir aún un riesgo mayor, como se ha venido insinuando en este texto: que el Derecho puede ser entendido como una forma arquetípica de lo literario, que se consolida narratológicamente. Esto es: el Derecho entendido o mejor aún comprendido, como un arquetipo literario que se despliega en un parquet narrativo.

${ }^{28}$ Galeano, E.: “El tigre azul y otros artículos”, La Habana, Editorial de Ciencias Sociales, 2015.pp. 
Es decir, la praxis jurídica tanto como la literaria, ostentan claramente un sustrato expresivo que se despliega en base a una matriz narrativa, como lo señalara insistentemente y lúcidamente, nuestro recordado Calvo González. ${ }^{29}$

En tal sentido el autor, que fue el artífice más conspicuo de la llamada Teoría narrativista del Derecho, sostuvo que el Derecho posee naturaleza y propiedades narrativas.

Su postulación teórica, como se sabe, le llevó a tratar de explicar y comprender otros momentos y expresiones del fenómeno jurídico y de su praxis productiva, interpretativa y de aplicación, que no se limitan a efectuar meras formulaciones narrativas a problemas más o menos puntuales de argumentación jurídica, en donde la producción narrativa parece necesariamente obvia.

De tal manera, la teoría calviana implica, entre otros singulares aspectos, abordar profundamente temas de crucial importancia, tales como el referido a la verdad en el proceso y también la instancia final del tránsito procesal, en donde culmina asistiéndose a lo que Calvo González denomina "la verdad de la verdad judicial”, así como trabajar prolija y delicadamente el concepto de “ coherencia narrativa”, en el que propugna “...un constructo discursivo capaz de otorgar sentido, esto es, ... un tipo de razonamiento acerca del material probatorio sobre la alegación de los hechos destinado a suministrar un criterio "de verdad", que justamente reside en el modelo discursivo de una historia sobre la acción de los hechos ( resultancia) y acerca de los "hechos en acción" (ocurrencia) con valor de sentido dentro del artificio narrativo ( relato) y que discurren y que los cuenta ( narración)[...]" 30

Por ende, la Teoría narrativista, expresa que el constructo discursivo, del Derecho con Literatura, siempre en clave "narrativa”, podrá solamente y tan solo, actuar como un criterio de "verosimilitud", producto de su enclave hermenéutico, lo que se asume absolutamente en el presente y acotado texto.

\section{CONCLUSIÓN}

Finalmente, se efectuarán algunas conclusiones referentes a la propuesta que se transmite en el presente texto: Huelga decir que el presente trabajo se abordó desde una perspectiva "crítica", en sentido estricto. Tal abordaje, condiciona por lógica tanto el enfoque expositivo, como el argumentativo y conclusivo.

${ }^{29}$ Calvo González, J.: “Proceso y Narración. Teoría y práctica del narrativismo jurídico”. Palestra Editores, Lima, Perú, 2019, particularmente pp. 231 y ss.

${ }^{30}$ Calvo González, J.: ob. cit.,nota 30, , pp 241. 
En tal contexto, se estiman procedentes las siguientes conclusiones:

1.- El Derecho debe asumirse como una práctica socio-cultural-discursiva productora de sentido, constitutiva e instituyente, que se desarrolla en el marco interactivo social. Por lo demás, su matriz generativa puede decirse que es multívoca, y su apreciación epistémica, opera en el marco de la interdisciplinariedad, lo que asegura réditos de singular valía.

2. - Por influjo de la supuesta" racionalidad posmoderna”, y si se quiere aprovechar su vinculación con la metáfora sociológica de la "liquidez" baumaniana, aún vigente pero hoy en términos de probable repliegue, queda claro que tanto el discurso como todo lo concerniente a “lo jurídico", resultaron afectados por la falta de certeza y la policontextualidad, de forma paralela a como lo fueron la Literatura y otros constructos culturales.

3.- Ello ha sido así también, porque se ha enfatizado que el Derecho es una forma arquetípica de Literatura, lo que consolida y refuerza la categoría de Derecho con Literatura, creada por José Calvo González.

4.- El marco pandémico aún en proceso y sin miras cierta de finalización, pese a la semántica inventada para su comunicación, ha de provocar también especiales cambios estructurales en el marco de "lo jurídico literario", que requerirán particular atención e instancias de profunda reflexión por parte de todos los operadores de la praxis, y particularmente de la Academia.

5- La aceptación o por lo menos la discusión de las complejidades sociales vigentes, apreciadas de la manera que Luhmann la propone, esto es en una perspectiva sistémica, junto con el abordaje "hermenéutico" que se sugiere en este trabajo y que controvierte radicalmente la idea de que el Derecho pueda constituir algo puramente racional, asociado racional con empírico y lógico metodológico, completan un set de herramientas sin duda proficuas para estos estudios, que además ayudan a mitigar la consabida opacidad del constructo jurídico.

6. - En el epicentro del tema, habrá de ponerse especial atención al concepto de verdad emergente, y aplicable a la praxis jurídica, que deja de lado su ontología y absolutez, y pasa a ser visualizada como "verosimilitud", esto es, como algo probablemente verdadero.

7.- La perspectiva interdisciplinaria de la que deriva el emparejamiento del Derecho con Literatura, y considerara al Derecho como una forma arquetípica de Literatura, deja traslúcida su naturaleza y matriz narratológica, esto último tal como lo propusiera José Calvo González. En su interior anidan provechosos conceptos manejados por la Teoría Narrativista, tales como las peculiaridades de la denominada "coherencia narrativa", y aquella consecuencia derivada de ir 
DERECHO CON LITERATURA: UN ARQUETIPO LITERARIO EN TIEMPOS DE POSMO-PANDEMIA UN NEOLOGISMO ACASO INESPERADO

en pos de la hermenéutica, esto es la "verosimilitud", una aproximación a la verdad, como opuesta a la verdad en sentido ontológico.

Finalmente es claro, que la naturaleza claramente breve del presente trabajo, deja por el camino muchas cuestiones; algunas ni siquiera expuestas, otras tan solo consecuencias posibles de lo que aquí se ha dicho.

Quizás el mérito principal del texto, si es que lo tiene, sea pues su irresolución, como principio de un camino para seguir pensando.

\section{REFERENCIAS}

Bauman, Z. : “Modernidad líquida”, FCE, Argentina, 2004, (3ª- Ed).

Beck, U. cit. por Acosta, Y. en : Acosta: Y. "Sujeto y democratización en el contexto de la globalización. Perspectivas críticas desde América Latina. Editorial Nordan-Comunidad, Montevideo, 2005.

Calvo González, J.: “Proceso y Narración. Teoría y práctica del narrativismo jurídico”. Palestra Editores, Lima, Perú, 2019.

Cárcova, C. Ma..: “ La opacidad del Derecho”, Madrid, Trotta, 2006.

Cárcova, C. Ma..: “Las Teorías Pos positivistas”, Lexis Nexis, Buenos Aires, 2007, pp. 162.

Meliante Garcé, L.: "La Crítica jurídica Latinoamericana. De la invisibilidad a su consideración en la Doctrina Nacional, en Revista de la Facultad de Derecho No. 36. FCU, Montevideo, 2014, pp.272.

Cárcova, C.Ma.: "Verdad o verosimilitud”, Conferencia Plenaria, del XXIX Congreso de la Asociación Argentina de Filosofía del Derecho, 1,2 y 3 de Octubre de 2015, Ushuaia, Argentina. 2015.

Doerdelein Schwartz, G.: ibídem, y Meliante, L. y Sosa, M.J.: “Derecho y literatura: Interdisciplinariedad, cruces inevitables y réditos posibles", en Cuadernos del Claeh, Vol. 37, No. 108, 2018, h ttps://doi.org/10.29192/CLAEH.37.2.3.

Doerdelein Schwartz, G.: “Um admirável novo direito: autopiese, risco e altas tecnologías sanitarias. En Direito \& literatura. Reflexôes teóricas, Porto Alegre: Livraria do Advogado, 2008, pp. 192-.208.

Eco, U.: “De la estupidez a la locura. Crónicas para el futuro que nos espera”. Barcelona, Lumen, 2016.

Meliante, L.: Latinoamérica en la región: “Sociedad líquida”, decisión judicia y política. Un conflicto agudo apenas disimulado", en Revista Anales de la Facultad de Ciencias Jurídicas y Sociales. Universidad Nacional de La Plata. UNLP, No. 48- V 15, , pp. 1075-1105. 
Galeano, E.: “El tigre azul y otros artículos”, La Habana, Editorial de Ciencias Sociales, 2015.

García Rubio, M.P.: "Sociedad liquida y codificación", en Anuario de Derecho Civil,V.69, No.3, Ministerio de Justicia, Boletín Oficial del Estado,2016, España,pp.746,Meliante Garcé, L." Latinoamérica en la región: Sociedad liquida, decisión judicial y política. Un conflicto agudo apenas disimulado.", en Revista Anales Revista Anales de la Facultad de Ciencias Jurídicas y Sociales. Universidad Nacional de La Plata. UNLP, No. 48/2018, 2015, pp.1078 y ss.

Honneth, A. (2009): «Lo otro de la justicia. Habermas y el desafío ético del posmodernismo». En Honneth, A. Crítica del agravio moral. Patologías de la sociedad contemporánea, Buenos Aires: Fondo de Cultura Económica, 2009.

Mateo Girón, J. (2009): “. Zygmunt Bauman: una lectura líquida de la posmodernidad”. Relaciones internacionales (SI), No.9, nov.2009, ISSN16993950, disponible en :

$\mathrm{http} / / \mathrm{www} / \mathrm{info} / \mathrm{ojs} /$.index. php?jorunal=RelacionesInternacionales=page=article=op=view. $p a t h \%$ $5 B \% 5 D=128$.

Marí, E.: «Derecho y literatura. Algo de lo que sí se puede hablar pero en voz baja», DOXA, 21, II, 253-287, 2008.

Meliante Garcé, L..: “Contribución para una perspectiva filosóficamente crítica de la unidad básica del Derecho de Familia", Anuario de Derecho de familia y Sucesiones", No. 3. FCU, Montevideo, 2015,pp. 149-161; Meliante Garcé, L.: “La sociedad líquida y el derecho al Derecho”, en Revista Crítica de Derecho Privado, La Ley-Uruguay, 2017.

Streck, L.: “Crítica Hermenêutica do Direito”, Porto Alegre, Livraria do Advogado, Editora, 2016.

Artigo convidado

\section{COMO FAZER REFERÊNCIA AO ARTIGO (ABNT):}

GARCÉ, Luis Meliante. Direito E Literatura. Um Arquétipo Literário em Tempos Pós-Pandêmicos - Um Neologismo de Acaso Inesperado. Revista Eletrônica do Curso de Direito da UFSM, Santa Maria, RS, v. 15, n. 2, e64341, maio/ago. 2020. ISSN 1981-3694. DOI: http://dx.doi.org/10.5902/1981369464341. Disponível em: https://periodicos.ufsm.br/revistadireito/article/view/64341 Acesso em: dia mês. ano.

Direitos autorais 2020 Revista Eletrônica do Curso de Direito da UFSM

Editores responsáveis: Rafael Santos de Oliveira e Angela Araujo da Silveira Espindola

Esta obra está licenciada com uma Licença Creative Commons Atribuição-NãoComercial-SemDerivações 4.0 Internacional.

\section{SOBRE O AUTOR}

LUIS MELIANTE GARCÉ

El autor es Profesor Adjunto Efectivo de Teoría y Filosofía del Derecho, Profesor de pos graduación en la Maestría de Derecho de Daños (NDC) y del curso para Graduados de Teorías Críticas del Derecho, en la Facultad de Derecho de la Universidad de la República. Es Profesor Titular de la misma materia y de Escritura Académica III, en la Facultad de Derecho de la U-Claeh. (Facultad de Derecho de la Universidad del Centro Latinoamericano de Economía Humana). 